\title{
Dormant Origins, the Licensing Checkpoint, and the Response to Replicative Stresses
}

\author{
Debbie McIntosh and J. Julian Blow \\ Centre for Gene Regulation \& Expression, University of Dundee, Dow Street, Dundee DD1 5EH, \\ United Kingdom \\ Correspondence: j.j.blow@dundee.ac.uk
}

\begin{abstract}
Only $\sim 10 \%$ of replication origins that are licensed by loading minichromosome maintenance 2-7 (MCM2-7) complexes are normally used, with the majority remaining dormant. If replication fork progression is inhibited, nearby dormant origins initiate to ensure that all of the chromosomal DNA is replicated. At the same time, DNA damage-response kinases are activated, which preferentially suppress the assembly of new replication factories. This diverts initiation events away from completely new areas of the genome toward regions experiencing replicative stress. Mice hypomorphic for MCM2-7, which activate fewer dormant origins in response to replication inhibition, are cancer-prone and are genetically unstable. The licensing checkpoint delays entry into $S$ phase if an insufficient number of origins have been licensed. In contrast, humans with Meier-Gorlin syndrome have mutations in pre-RC proteins and show defects in cell proliferation that may be a consequence of chronic activation of the licensing checkpoint.
\end{abstract}

$\mathrm{R}^{\mathrm{en}}$ eplicating the large amount of DNA in eukaryotic cells is a complex task, requiring the activation of hundreds or thousands of origins spread throughout the genome. To maintain genetic stability, it is essential that during $S$ phase genomic DNA is precisely duplicated, with no sections of DNA left unreplicated and no section ofDNA replicated more than once. To prevent rereplication, cells divide the process of DNA replication into two non-overlapping phases. Prior to $S$ phase, origins are licensed by the binding of minichromosome maintenance 2-7 (MCM2-7) double hexamers (Gillespie et al. 2001; Blow and Dutta 2005; Arias and Walter 2007). During S phase, these are activated as the core of the CMG (Cdc45-MCM-GINS) replicative helicase

(Moyer et al. 2006; Ilves et al. 2010). Prior to the onset of S phase, licensing proteins are downregulated or inhibited, so that no more origins can be licensed (Wohlschlegel et al. 2000; Tada et al. 2001; Li et al. 2003; Li and Blow 2005). One consequence of using this mechanism for preventing re-replication of DNA is that it is imperative that enough origins are licensed prior to S-phase entry, so that no regions of the genome remain unreplicated, even if some replication forks stall or some origins fail to initiate (Blow et al. 2011). Metazoan cells employ a licensing checkpoint to monitor that sufficient origins are licensed, inhibiting S-phase entry until this is established (Shreeram et al. 2002; Blow and Gillespie 2008).

Editors: Stephen D. Bell, Marcel Mechali, and Melvin L. DePamphilis

Additional Perspectives on DNA Replication available at www.cshperspectives.org

Copyright (C) 2012 Cold Spring Harbor Laboratory Press; all rights reserved; doi: 10.1101/cshperspect.a012955

Cite this article as Cold Spring Harb Perspect Biol 2012;4:a012955 
Here we review recent research showing how cells ensure complete genome duplication by licensing more replication origins in G1 than are normally used during $S$ phase. The otherwise dormant replication origins become important for ensuring the completion of DNA replication if replication forks stall or are inhibited during $\mathrm{S}$ phase. We also review research showing how the licensing checkpoint ensures that a large enough number of origins are licensed before cells embark on $S$ phase.

\section{DORMANT REPLICATION ORIGINS}

MCM2-7 complexes are loaded onto DNA in excess over the number normally used, with only $\sim 10 \%$ being used in an unperturbed $S$ phase (Burkhart et al. 1995; Donovan et al. 1997; Mahbubani et al. 1997; Blow et al. 2011; Wong et al. 2011). The rest normally remain dormant and are passively replicated by oncoming forks (Woodward et al. 2006; Ge et al. 2007). Dormant origins are fully capable of initiating, but are not essential for normal S-phase progression (Woodward et al. 2006). The existence of these dormant origins means that origin usage can change depending on the circumstance. Levels of chromatin-bound MCM2-7 can be reduced several-fold in Xenopus egg extracts, C. elegans, and in human cell lines without causing a significant effect on overall replication rates (Mahbubani et al. 1997; Edwards et al. 2002; Oehlmann et al. 2004; Ge et al. 2007; Ibarra et al. 2008). However, these "minimally licensed" cells fail to complete replication when challenged with exogenous replicative stress, suggesting a role for dormant origins in overcoming such stresses (Woodward et al. 2006; Ge et al. 2007; Ibarra et al. 2008).

Replication forks can be inhibited either by exposure to exogenous inhibitors or when they encounter impediments such as proteins tightly bound to DNA, chemically modified bases or DNA strand breaks. Often the problems can be overcome, and the inhibited forks can resume DNA synthesis. However, there are occasions where replication forks irreversibly collapse, which may be associated with the disassembly of replisome proteins from the DNA (Sirbu et al.
2011). Since new origins cannot be licensed after entry into S phase, cells must rely on previously licensed origins to overcome this issue. Replication forks travel bidirectionally, meaning that if a single fork stalls, a fork coming from the opposite direction can rescue this (Fig. 1A,B). However, when two converging forks stall, the genome between them is left in a compromised state, and if there is no dormant origin between the stalled forks, completing DNA replication will be difficult (Fig. 1C), possibly depending on recombination-dependent fork restart (Blow et al. 2011). However, if a dormant origin is activated between the stalled forks, this provides a simple mechanism for replication of all the intervening DNA (Fig. 1D) (Woodward et al. 2006; Ge et al. 2007).

The exact mechanism for regulating dormant origins is unclear. It has been known for many years that in response to fork slowing, there is an increased density of origins within clusters (Ockey and Saffhill 1976; Taylor 1977; Francis et al. 1985; Griffiths and Ling 1985; Anglana et al. 2003; Ge et al. 2007; Gilbert 2007; Blow et al. 2011; Borowiec and Schildkraut 2011; Karnani and Dutta 2011), indicating dormant origins have fired within these clusters. It is likely that firing of particular origins within a single cluster is a stochastic process, which can explain the observed cell-to-cell variation in origin use (Anglana et al. 2003; Blow and Ge 2009; Borowiec and Schildkraut 2011). Since licensed origins are inactivated when they are passively replicated by oncoming forks, they are normally inactivated before they have time to initiate. Therefore, a reduction in fork elongation rate increases the length of time before inactivation of dormant origins, increasing the probability that they will initiate. Computer simulation of a $250-\mathrm{kb}$ origin cluster showed that stochastic firing of origins can provide a good approximation to observed patterns of dormant origin firing if there are $\sim 3$ dormant origins for each origin that fires under unstressed conditions (Blow and Ge 2009). The model also shows how dormant origins can allow replication to complete even if some forks stall irreversibly. This provides a simple explanation for how replication origin firing is regulated, which 
A Single fork stall—no dormant origin

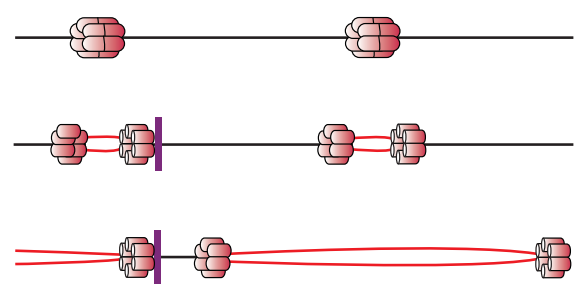

C Double fork stall—no dormant origin
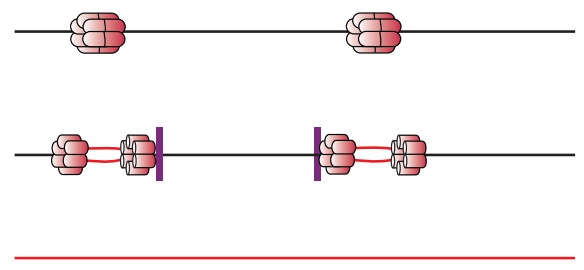

B Single fork stall—dormant origin not required

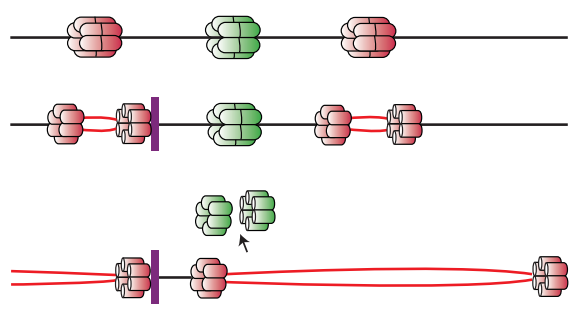

D Double fork stall—dormant origin required

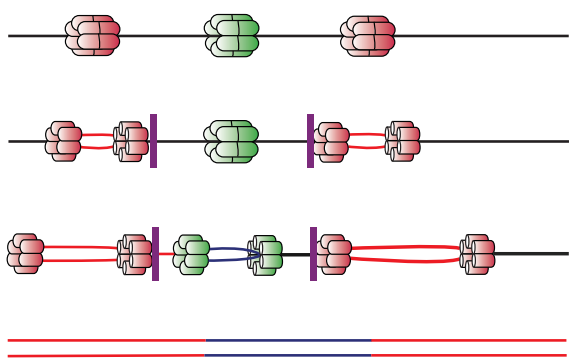

Figure 1. The effect of fork stalling on completion of replication. A small segment of chromosomal DNA is shown with two efficient licensed origins red hexamers) plus an optional dormant origin (green hexamers). Fork stalling is indicated by a vertical purple bar. $(A)$ One fork stalls, but all the intervening DNA is replicated by the fork originating at an adjacent origin. $(B)$ A dormant origin is inactivated by a fork coming from the right. $(C)$ Each of the two converging forks stall without a dormant origin between them. Replication cannot be completed because no new MCM2-7 complexes can be loaded onto DNA once S phase has begun. (D) Two converging forks stall, but a dormant origin between them allows replication to be completed.

simultaneously provides protection against replicative stress while minimizing the cost of using large numbers of replication forks (Blow and Ge 2009; Blow et al. 2011). Consistent with this interpretation, there is a correlation between the degree of fork slowing and the overall increase in origin density (Ge et al. 2007; Courbet et al. 2008).

Although dormant origin firing can occur as a consequence of purely stochastic processes, it is likely that it is also modulated by other regulatory mechanisms. In response to fork stalling, the DNA damage kinases ATR and Chk1 are activated (Branzei and Foiani 2005; Lambert and Carr 2005). Inhibition of ATR or Chk1 results in an increase in origin density, even in the absence of stress (Miao et al. 2003; Marheineke and Hyrien 2004; Syljuasen et al. 2005; Woodward et al. 2006; Ge et al. 2007; Karnani and
Dutta 2011). One explanation for this behavior is that dormant origins are activated as a consequence of increased fork stalling that occurs in the absence of normal ATR and Chk1 activity (Zachos et al. 2003). However, it is also possible that the low levels ATR/Chk1 active even in the absence of exogenous replicative stresses, play a role in suppressing dormant origins. In addition, low levels of Chk1 preferentially suppresses new origin firing in clusters yet to engage in replication, allowing dormant origins the chance to initiate in the clusters where fork stalling has occurred (see next section).

Once cells have progressed through S phase in the presence of replicative stresses, there is evidence that the usage of origins in the next $\mathrm{S}$ phase will be changed (Courbet et al. 2008). After growing cells under conditions in which forks could only move slowly, which promoted 
a high rate of initiation at dormant origins, cells were synchronized in mitosis and replated into fresh medium that allowed fast fork progression. In the first $S$ phase after replating, the overall initiation density dropped, as expected by the stochastic mechanism described above. When a particular locus around the AMPD gene was examined, initiation did not occur predominantly at what is normally the most efficient origin, oriGNAI3, but was distributed among the dormant origins as well as oriGNAI3. Only in the second $S$ phase after the increase in fork speed was the dominance of oriGNAI3 regained and the relative efficiency of the dormant origins decreased. Therefore, it appears that cells acquire a memory of dormant origin use and can adapt to replicative stress by raising the efficiency of origins that are normally dormant (less efficient) (Blow and Ge 2008; Courbet et al. 2008).

The use of dormant origins probably provides the first line of defense against slowed fork elongation and fork stalling. The importance of dormant origins in ensuring genome stability has been shown by their role in suppressing tumorigenesis. Mice hypomorphic for either MCM2 or MCM4 have reduced levels of chromatin-bound MCM2-7, resulting in a reduction in the number of dormant origins (Pruitt et al. 2007; Shima et al. 2007; Kunnev et al. 2010; Kawabata et al. 2011; Klotz-Noack and Blow 2011). Cells from MCM hypomorphic mice suffer from increased fork stalling and increased Rad51 and FancD2 foci, indicative of DNA damage, even in the absence of exogenous stress (Kunnev et al. 2010; Kawabata et al. 2011). These mice fail to deal normally with spontaneous damage caused by endogenous factors and this is likely to explain their dramatic increase in tumor formation. This suggests that dormant origins play an important role as tumor suppressors and that failure to activate dormant origins in response to endogenous replicative stresses can result in DNA damage and tumor formation.

\section{REPLICATION FACTORIES}

In metazoan cells, clusters of 2-5 adjacent origins initiate simultaneously during $\mathrm{S}$ phase (Jackson and Pombo 1998; Gillespie and Blow
2010). One or more clusters are arranged into DNA domains comprising $\sim 1 \mathrm{Mb}$ of DNA and roughly 6-12 replicons, each replicon typically replicating $50-150 \mathrm{~kb}$. Different clusters of origins initiate at varying times throughout $S$ phase, giving rise to a timing program (Dimitrova and Gilbert 1999; Zink 2006). The DNA within each domain can be visualized as individual foci, thousands of which can be visualized during each S phase. As each focus becomes activated for replication, it becomes associated with replication proteins to form a replication factory (Hozak et al. 1993; Leonhardt et al. 2000; Kitamura et al. 2006). Early S-phase factories are all similar in size with a diameter of roughly $150 \mathrm{~nm}$, and similar numbers are detected in all early S-phase nuclei (Blow et al. 2011). It is currently unknown if factories are physical structures where the fork proteins are organized into a superstructure or whether the foci as formed as a result of the organization of the DNA into higher-order chromatin structure.

It has recently been shown that these factories are regulated in response to replicative stresses. In response to low levels of replicative stress, there is an increase in the number of replication forks per factory that corresponds to the activation of dormant origins (Ge and Blow 2010). This increase in initiation leads to the increased fork density seen by DNA fiber analysis. If the overall rate of replication of DNA domains were reduced by replication fork inhibition, and if the rate at which new factories are activated were to remain constant, the result should be an increase in the number of active factories. However, the opposite is actually observed: inhibition of replication forks causes a reduction in the number of active factories (Cseresnyes et al. 2009; Ge and Blow 2010). Experiments examining factory dynamics after replication forks are inhibited showed that the reduction in factory number is a result of a reduction in the rate at which new replication factories are activated and depends on Chk1 (Fig. 2) (Ge and Blow 2010). ATR is activated in response to slowed fork progression or stalling and in turn activates Chk1 kinase activity (Branzei and Foiani 2005; Lambert and Carr 2005). By preferentially inhibiting the activation of new replication factories, Chk1 

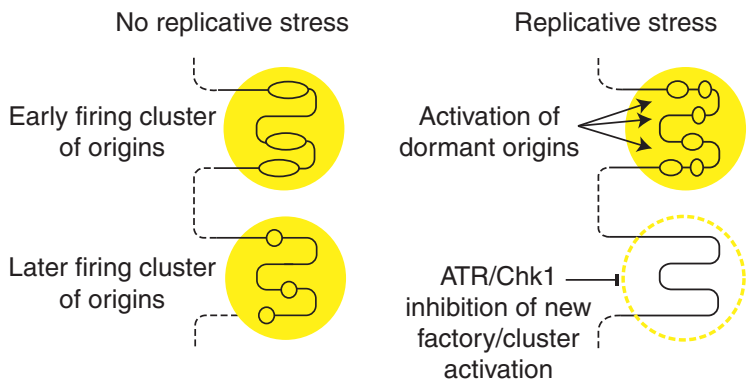

Figure 2. Model for how cells respond to low levels of replicative stress. Two adjacent clusters of origins (factories bounded by yellow circles) are shown on a single piece of DNA (black lines). Under normal circumstances (left), the upper factory is activated slightly earlier than the factory below, and each initiates three origins. Under low levels of replicative stress ( right), replication forks are inhibited in the earlier replicating cluster, which promotes the firing of dormant origins as a direct consequence of stochastic origin firing. Replicative stress activates DNA damage checkpoint kinases, which preferentially inhibit the activation of the unfired later clusters/new factories.

suppresses activation of origins in clusters yet to begin replicating but allows dormant origins to fire in currently replicating clusters that may have encountered replication stress ( $\mathrm{Ge}$ and Blow 2010; Blow et al. 2011).

Very little is known about how replication factories are regulated and it is currently not known how Chk1 is able to distinguish between active clusters and those already replicating. The activation of new factories is highly sensitive to varying cyclin-dependent kinase (CDK) activity. When CDK activity was reduced using the drug roscovitine, the number of factories was also reduced (Thomson et al. 2010). Two different possibilities have been proposed to explain this effect (Ge and Blow 2010; Gillespie and Blow 2010; Thomson et al. 2010; Blow et al. 2011). CDKs are directly required for individual replication origins to fire, and it is possible that the firing of the first origin within a cluster might propagate a change throughout the cluster to facilitate initiation at other origins within the cluster. A reduction in CDK level would lower the overall initiation rate and thereby reduce the activation of new factories. Downstream targets of Chk1, such as p53 and Cdc25 could reduce CDK activity and thereby reduce the rate of activation of new factories. An alternative possibility is that CDK activity plays a direct role in factory regulation, by phosphorylating factoryspecific substrates (such as, for example, proteins involved in chromatin remodeling) dis- tinct from substrates that are required for the firing of individual origins. These factory-specific substrates might then be directly inhibited by Chk1 in response to replicative stresses ( $\mathrm{Ge}$ and Blow 2010; Gillespie and Blow 2010; Thomson et al. 2010; Blow et al. 2011).

The regulation of replication at the factory level is important for ensuring that the genome is completely replicated. By preferentially inhibiting the activation of new replication factories, Chk1 can still allow dormant origins to fire stochastically in factories that are experiencing replicative stress. This effectively directs replication activity to regions of the genome encountering stress, by activating dormant origins in factories where forks are encountering problems. Correct regulation of this process requires the proper operation of DNA damage and cell cycle checkpoint responses. As these systems are often compromised in cancer cells, they may be unable to correctly regulate dormant origins and replication factories when replication fork progress is inhibited. It is possible that this may explain the sensitivity of some cancer cells to chemotherapeutic drugs that target the process of DNA replication (Blow and Gillespie 2008; Blow et al. 2011). It is also possible that chromosome fragile sites, which are prone to breakage as a result of replication fork failure, represent regions where dormant origins are either inefficiently licensed or inefficiently activated (Letessier et al. 2011; Ozeri-Galai et al. 2011; Debatisse et al. 2012). 
D. McIntosh and J.J. Blow

\section{THE LICENSING CHECKPOINT}

To prevent re-replication of regions of chromosomal DNA, it is essential that once cells pass the G1-S-phase boundary, no further origins are licensed (Blow and Dutta 2005; Arias and Walter 2007). Entering S phase with too few origins would result in a reduced number of dormant origins and would require forks to replicate longer sections of DNA without stalling (Blow and Ge 2009). It would therefore be better for cells to delay entry into $S$ phase if they do not have a sufficiently large number of licensed origins. It has been shown that several different cell types employ a "licensing checkpoint" to achieve this (Shreeram et al. 2002; Gillespie et al. 2007; Blow and Gillespie 2008). The S phase delay characteristic of the licensing checkpoint has been observed when the loading of MCM2-7 onto DNA is reduced in a range of different ways: by knockdown of ORC, Cdc6 Ctd1 or MCM2-7 by RNAi, or inhibition of Cdt1 by geminin (Shreeram et al. 2002; Feng et al. 2003; Machida et al. 2005; Gillespie et al. 2007; Liu et al. 2009; Nevis et al.2009). Many cancer cells are defective in this checkpoint and can enter S phase despite a severe reduction in the number of origins that have been licensed (Shreeram et al. 2002; Feng et al. 2003; Liu et al. 2009; Nevis et al. 2009), a feature that may contribute to the genetic instability typically detected in cancer cells (Fig. 3) (Blow and Gillespie 2008).

Under normal circumstances, progression through the restriction point into $S$ phase depends on the CDK-dependent phosphorylation of Rb, which abolishes its inhibition of E2F and promotes transcription of S-phase genes. The G1 arrest observed in cells that have engaged the licensing checkpoint is associated with low CDK4/6-Cyclin D activity, low CDK2-Cyclin E activity and $\mathrm{Rb}$ hypophosphorylation, suggesting that the licensing checkpoint prevents progression through the restriction point (Fig. 4) (Shreeram et al. 2002; Machida et al. 2005; Teer et al. 2006; Liu et al. 2009; Nevis et al. 2009). The way that the degree of licensing is sensed by the checkpoint is currently unknown, but it appears to converge on CDK down-regulation by several different routes. One common route appears to be the p53-dependent activation of CDK

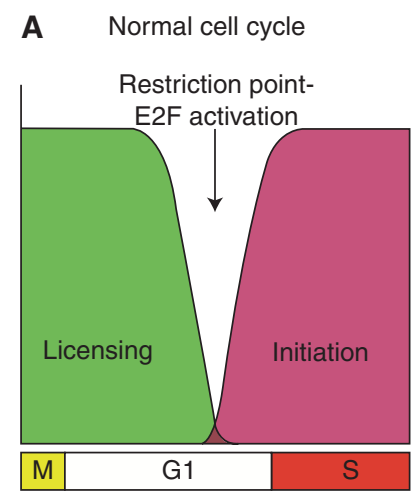

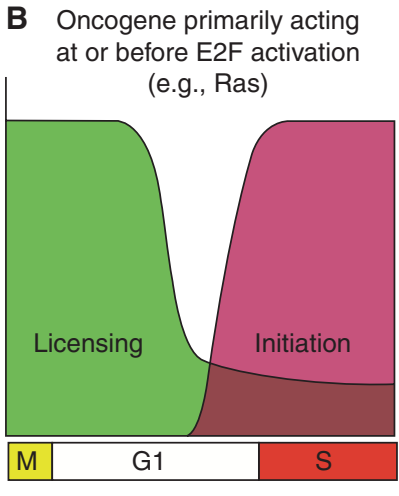

Re-replication

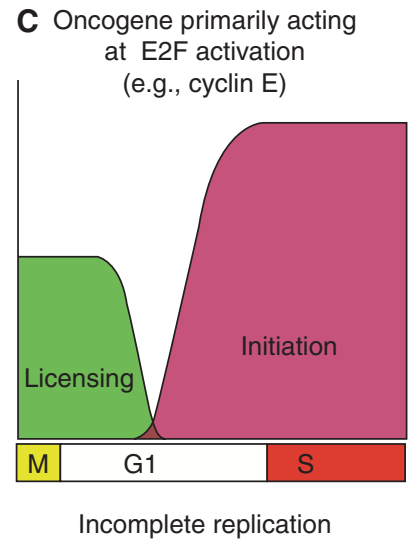

Figure 3. How oncogene activation might normally disrupt licensing control. Progression through the cell cycle (as shown in the lower bar) depends on sequential activation of the licensing system (green) and initiation activities (fuchsia). (A) In normal cells, there is no significant overlap between licensing and initiation activities. The transition from the licensing state to the initiation state occurs around the restriction point. $(B)$ If an oncogene is constitutively expressed that acts upstream of the restriction point, cells may be unable to fully repress licensing activity during $S$ phase, potentially leading to re-replication of DNA. $(C)$ If an oncogene is constitutively expressed that acts downstream of the restriction point, cells may not be able to license a sufficiently large number of origins before progressing into S phase, potentially leading to incomplete replication of DNA. See Blow and Gillespie (2008) for more discussion of these potential effects. 
The Response to Replicative Stresses
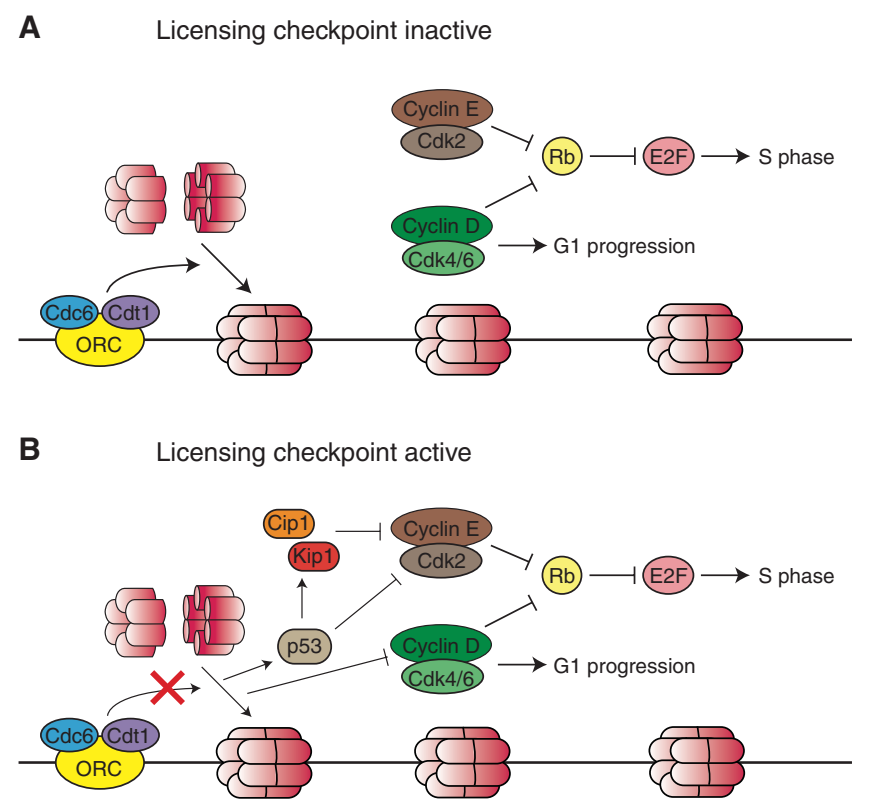

Figure 4. The licensing checkpoint. A piece of DNA containing several origins is denoted by the black line. $(A)$ When licensing occurs, ORC, Cdc6, and Cdt1 promote the loading of MCM2-7 (red hexamers) onto DNA. This allows normal activation of Cdk4/6 and Cdk2 kinases, and subsequent activation of E2F by Rb phosphorylation. $(B)$ When the licensing is inhibited, the licensing checkpoint is activated, causing suppression of cyclin D transcription and activation of p53, resulting in induction and Cip1 and Kip1 and inhibition of activating Cdk2 phosphorylation.

inhibitors p21 ${ }^{\text {Cip1 }}$ and p27 ${ }^{\text {Kip1 }}$ (Shreeram et al. 2002; Machida et al. 2005; Teer et al. 2006; Liu et al. 2009). A second p53-dependent pathway involves loss of phosphorylation at Thr160 in the activation $\mathrm{T}$ loop of CDK2, accompanied by delayed nuclear accumulation of CDK2 protein in late G1 (Nevis et al. 2009). Depletion of p53 in primary cells abolished the licensing checkpoint, promoting Rb hyperphosphorylation and E2F transcriptional activity. There also appears to be other p53-independent mechanisms by which CDK activity is reduced when the licensing checkpoint is engaged, as RNAi knockdown of components of the licensing system directly suppressed cyclin D1 transcription and lowered CDK4/6 kinase activity (Liu et al. 2009). Another way by which defective origin licensing delays S-phase CDK activation has been demonstrated in Xenopus egg extract. The nucleoporin ELYS associates with MCM2-7 on chromatin and if licensing is inhibited (for ex- ample, by geminin addition or MCM2-7 depletion), the association of ELYS with chromatin is delayed (Gillespie et al. 2007; Khoudoli et al. 2008). Since ELYS is required on chromatin for nuclear envelope formation, it is ultimately required for $\mathrm{CDK}$ activation, the initiation of DNA replication, and the activation of geminin, thereby creating a feed-forward loop to promote $\mathrm{S}$-phase progression only once adequate origin licensing has occurred.

Mutations in genes encoding pre-RC proteins required for replication licensing (ORC1, ORC4, ORC6, CDT1, and CDC6) have been identified in patients with the genetic disorder Meier-Gorlin syndrome (Bicknell et al. 2011a,b; Klingseisen and Jackson 2011; de Munnik et al. 2012; Kuo et al. 2012). Cells from these patients have a delayed G1 progression, most likely due to the activation of the licensing checkpoint, and a prolonged $S$ phase. These delays in cell cycle progression result in reduced cell numbers, 
potentially explaining the primordial dwarfism phenotype. This provides evidence that the licensing checkpoint is operational in humans.

It is currently unclear why humans with Meier-Gorlin syndrome show cell proliferation defects while mice hypomorphic for MCM2-7 are cancer-prone. One possibility is that this represents a difference between mice and humans. Alternatively, the licensing checkpoint might respond less strongly to defects in MCM2-7 than to defects in other pre-RC proteins (ORC, Cdc6, or Cdt1). A third possibility is that the licensing defect in the MCM2-7 hypomorphic mice might be weaker than in Meier-Gorlin syndrome and may not be severe enough to reproducibly activate the licensing checkpoint (Klotz-Noack and Blow 2011). Indeed, MCM2-7 hypomorphic mice do show some defects in cell proliferation associated with a reduction in the number of stem cells (Pruitt et al. 2007).

The reliance of the licensing checkpoint on p53 and Rb control systems that are often lost in cancer cells can potentially explain why the licensing checkpoint is not operational in cancerderived cell lines. Since E2F cannot be repressed by the licensing checkpoint, cancer cells lose the ability to inhibit progression into $S$ phase. Defects in the licensing checkpoint could contribute to the genomic instability often detected in cancer cells, as cells entering $S$ phase with too few origins have increased chances of fork stalling and DNA damage. The lack of licensing checkpoint in cancer cells also makes it a good anti-cancer target (Shreeram et al. 2002; Blow and Gillespie 2008). Small-molecule inhibitors of the replication licensing system would kill cancer cells by allowing them to progress into $S$ phase with an insufficient number of licensed origins. Normal cells would instead activate the licensing checkpoint and arrest temporarily in G1-like state, from where they could resume cell cycle progression once the drug is removed or metabolized.

\section{ACKNOWLEDGMENT}

J.J.B. is supported by CRUK grant C303/A7399.

\section{REFERENCES}

Anglana M, Apiou F, Bensimon A, Debatisse M. 2003. Dynamics of DNA replication in mammalian somatic cells: Nucleotide pool modulates origin choice and interorigin spacing. Cell 114: 385-394.

Arias EE, Walter JC. 2007. Strength in numbers: Preventing rereplication via multiple mechanisms in eukaryotic cells. Genes Dev 21: 497-518.

Bicknell LS, Bongers EM, Leitch A, Brown S, Schoots J, Harley ME, Aftimos S, Al-Aama JY, Bober M, Brown PA, van Bokhoven H, Dean J, et al. 2011a. Mutations in the pre-replication complex cause Meier-Gorlin syndrome. Nat Genet 43: 356-359.

Bicknell LS, Walker S, Klingseisen A, Stiff T, Leitch A, Kerzendorfer C, Martin CA, Yeyati P, Al Sanna N, Bober M, Johnson D, Wise C, et al. 2011b. Mutations in ORC1, encoding the largest subunit of the origin recognition complex, cause microcephalic primordial dwarfism resembling Meier-Gorlin syndrome. Nat Genet 43: 350355.

Blow JJ, Dutta A. 2005. Preventing re-replication of chromosomal DNA. Nat Rev Mol Cell Biol 6: 476-486.

Blow JJ, Ge XQ. 2008. Replication forks, chromatin loops and dormant replication origins. Genome Biol 9: 244.

Blow JJ, Ge XQ. 2009. A model for DNA replication showing how dormant origins safeguard against replication fork failure. $E M B O$ Rep 10: 406-412.

Blow JJ, Gillespie PJ. 2008. Replication licensing and cancer-a fatal entanglement? Nat Rev Cancer 8: 799-806.

Blow JJ, Ge XQ, Jackson DA. 2011. How dormant origins promote complete genome replication. Trends Biochem Sci 36: 405-414.

Borowiec JA, Schildkraut CL. 2011. Open sesame: activating dormant replication origins in the mouse immunoglobulin heavy chain (Igh) locus. Curr Op Cell Biol 23: 284292.

Branzei D, Foiani M. 2005. The DNA damage response during DNA replication. Curr Op Cell Biol 17: 568-575.

Burkhart R, Schulte D, Hu D, Musahl C, Gohring F, Knippers R. 1995. Interactions of human nuclear proteins P1Mcm3 and P1Cdc46. Eur J Biochem 228: 431-438.

Courbet S, Gay S, Arnoult N, Wronka G, Anglana M, Brison O, Debatisse M. 2008. Replication fork movement sets chromatin loop size and origin choice in mammalian cells. Nature 455: 557-560.

Cseresnyes Z, Schwarz U, Green CM. 2009. Analysis of replication factories in human cells by super-resolution light microscopy. BMC Cell Biol 10: 88.

Debatisse M, Le Tallec B, Letessier A, Dutrillaux B, Brison O. 2012. Common fragile sites: Mechanisms of instability revisited. Trends Genet 28: 22-32.

de Munnik SA, Bicknell LS, Aftimos S, Al-Aama JY, van Bever Y, Bober MB, Clayton-Smith J, Edrees AY, Feingold M, Fryer A, van Hagen JM, Hennekam RC, et al. 2012. Meier-Gorlin syndrome genotype-phenotype studies: 35 individuals with pre-replication complex gene mutations and 10 without molecular diagnosis. Eur J Hum Genet 6: 598-606. 
The Response to Replicative Stresses

Dimitrova DS, Gilbert DM. 1999. The spatial position and replication timing of chromosomal domains are both established in early G1 phase. Mol Cell 4: 983-993.

Donovan S, Harwood J, Drury LS, Diffley JF. 1997. Cdc6pdependent loading of $\mathrm{Mcm}$ proteins onto pre-replicative chromatin in budding yeast. Proc Natl Acad Sci 94: 5611-5616.

Edwards MC, Tutter AV, Cvetic C, Gilbert CH, Prokhorova TA, Walter JC. 2002. MCM2-7 complexes bind chromatin in a distributed pattern surrounding the origin recognition complex in Xenopus egg extracts. J Biol Chem 277: 33049-33057.

Feng D, Tu Z, Wu W, Liang C. 2003. Inhibiting the expression of DNA replication-initiation proteins induces apoptosis in human cancer cells. Cancer Res 63: 7356-7364.

Francis D, Davies ND, Bryant JA, Hughes SG, Sibson DR, Fitchett PN. 1985. Effects of psoralen on replicon size and mean rate of DNA synthesis in partially synchronized cells of Pisum sativum L. Exp Cell Res 158: 500-508.

Ge XQ, Blow JJ. 2010. Chk1 inhibits replication factory activation but allows dormant origin firing in existing factories. J Cell Biol 191: 1285-1297.

Ge XQ, Jackson DA, Blow JJ. 2007. Dormant origins licensed by excess $\mathrm{Mcm} 27$ are required for human cells to survive replicative stress. Genes Dev 21: 3331-3341.

Gilbert DM. 2007. Replication origin plasticity, Taylormade: Inhibition vs recruitment of origins under conditions of replication stress. Chromosoma 116: 341-347.

Gillespie PJ, Blow JJ. 2010. Clusters, factories and domains-the complex structure of S phase comes into focus. Cell Cycle 9: 3218-3226.

Gillespie PJ, Li A, Blow JJ. 2001. Reconstitution of licensed replication origins on Xenopus sperm nuclei using purified proteins. BMC Biochem 2: 15.

Gillespie PJ, Khoudoli GA, Stewart G, Swedlow JR, Blow JJ. 2007. ELYS/MEL-28 chromatin association coordinates nuclear pore complex assembly and replication licensing. Curr Biol 17: 1657-1662.

Griffiths TD, Ling SY. 1985. Effect of ultraviolet light on thymidine incorporation, DNA chain elongation and replicon initiation in wild-type and excision-deficient Chinese hamster ovary cells. Biochim Biophys Acta 826: 121-128.

Hozak P, Hassan AB, Jackson DA, Cook PR. 1993. Visualization of replication factories attached to nucleoskeleton. Cell 73: $361-373$.

Ibarra A, Schwob E, Mendez J. 2008. Excess MCM proteins protect human cells from replicative stress by licensing backup origins of replication. Proc Natl Acad Sci 105: 8956-8961.

Ilves I, Petojevic T, Pesavento JJ, Botchan MR. 2010. Activation of the MCM2 -7 helicase by association with Cdc45 and GINS proteins. Mol Cell 37: 247-258.

Jackson DA, Pombo A. 1998. Replicon clusters are stable units of chromosome structure: Evidence that nuclear organization contributes to the efficient activation and propagation of S phase in human cells. J Cell Biol 140: 1285-1295.

Karnani N, Dutta A. 2011. The effect of the intra-S-phase checkpoint on origins of replication in human cells. Genes Dev 25: 621-633.
Kawabata T, Luebben S, Yamaguchi S, Ilves I, Matise I, Buske T, Botchan M, Shima N. 2011. Stalled fork rescue via dormant replication origins in unchallenged $\mathrm{S}$ phase promotes proper chromosome segregation and tumor suppression. Mol Cell 41: 543-553.

Khoudoli GA, Gillespie PJ, Stewart G, Andersen JS, Swedlow JR, Blow JJ. 2008. Temporal profiling of the chromatin proteome reveals system-wide responses to replication inhibition. Curr Biol 18: 838-843.

Kitamura E, Blow JJ, Tanaka TU. 2006. Live-cell imaging reveals replication of individual replicons in eukaryotic replication factories. Cell 125: 1297-1308.

Klingseisen A, Jackson AP. 2011. Mechanisms and pathways of growth failure in primordial dwarfism. Genes Dev 25: 2011-2024.

Klotz-Noack K, Blow JJ. 2011. A role for dormant origins in tumor suppression. Mol Cell 41: 495-496.

Kunnev D, Rusiniak ME, Kudla A, Freeland A, Cady GK, Pruitt SC. 2010. DNA damage response and tumorigenesis in Mcm2-deficient mice. Oncogene 29: 3630-3638.

Kuo AJ, Song J, Cheung P, Ishibe-Murakami S, Yamazoe S, Chen JK, Patel DJ, Gozani O. 2012. The BAH domain of ORC1 links H4K20me2 to DNA replication licensing and Meier-Gorlin syndrome. Nature 484: 115-119.

Lambert S, Carr AM. 2005. Checkpoint responses to replication fork barriers. Biochimie 87: 591-602.

Leonhardt H, Rahn HP, Weinzierl P, Sporbert A, Cremer T, Zink D, Cardoso MC. 2000. Dynamics of DNA replication factories in living cells. J Cell Biol 149: 271-280.

Letessier A, Millot GA, Koundrioukoff S, Lachages AM, Vogt N, Hansen RS, Malfoy B, Brison O, Debatisse M. 2011. Cell-type-specific replication initiation programs set fragility of the FRA3B fragile site. Nature 470: $120-$ 123.

Li A, Blow JJ. 2005. Cdt1 downregulation by proteolysis and geminin inhibition prevents DNA re-replication in Xenopus. EMBO J 24: 395-404.

Li X, Zhao Q, Liao R, Sun P, Wu X. 2003. The SCF(Skp2) ubiquitin ligase complex interacts with the human replication licensing factor Cdt1 and regulates Cdt1 degradation. J Biol Chem 278: 30854-30858.

Liu P, Slater DM, Lenburg M, Nevis K, Cook JG, Vaziri C. 2009. Replication licensing promotes cyclin D1 expression and G1 progression in untransformed human cells. Cell Cycle 8: 125-136.

Machida YJ, Teer JK, Dutta A. 2005. Acute reduction of an origin recognition complex (ORC) subunit in human cells reveals a requirement of ORC for Cdk2 activation. J Biol Chem 280: 27624-27630.

Mahbubani HM, Chong JP, Chevalier S, Thömmes P, Blow JJ. 1997. Cell cycle regulation of the replication licensing system: involvement of a Cdk-dependent inhibitor. J Cell Biol 136: 125-135.

Marheineke K, Hyrien O. 2004. Control of replication origin density and firing time in Xenopus egg extracts: Role of a caffeine-sensitive, ATR-dependent checkpoint. J Biol Chem 279: 28071-28081.

Miao H, Seiler JA, Burhans WC. 2003. Regulation of cellular and SV40 virus origins of replication by Chk1-dependent intrinsic and UVC radiation-induced checkpoints. J Biol Chem 278: 4295-4304. 
D. McIntosh and J.J. Blow

Moyer SE, Lewis PW, Botchan MR. 2006. Isolation of the Cdc45/Mcm2-7/GINS (CMG) complex, a candidate for the eukaryotic DNA replication fork helicase. Proc Natl Acad Sci 103: 10236-10241.

Nevis KR, Cordeiro-Stone M, Cook JG. 2009. Origin licensing and p53 status regulate Cdk2 activity during G1. Cell Cycle 8: $1952-1963$.

Ockey CH, Saffhill R. 1976. The comparative effects of short-term DNA Inhibition on replicon synthesis in mammalian cells. Exp Cell Res 103: 361-373.

Oehlmann M, Score AJ, Blow JJ. 2004. The role of Cdc6 in ensuring complete genome licensing and S phase checkpoint activation. J Cell Biol 165: 181-190.

Ozeri-Galai E, Lebofsky R, Rahat A, Bester AC, Bensimon A, Kerem B. 2011. Failure of origin activation in response to fork stalling leads to chromosomal instability at fragile sites. Mol Cell 43: 122-131.

Pruitt SC, Bailey KJ, Freeland A. 2007. Reduced Mcm2 expression results in severe stem/progenitor cell deficiency and cancer. Stem Cells 25: 3121-3132.

Shima N, Alcaraz A, Liachko I, Buske TR, Andrews CA, Munroe RJ, Hartford SA, Tye BK, Schimenti JC. 2007. A viable allele of $\mathrm{Mcm} 4$ causes chromosome instability and mammary adenocarcinomas in mice. Nat Genet 39: 93-98.

Shreeram S, Sparks A, Lane DP, Blow JJ. 2002. Cell typespecific responses of human cells to inhibition of replication licensing. Oncogene 21: 6624-6632.

Sirbu BM, Couch FB, Feigerle JT, Bhaskara S, Hiebert SW, Cortez D. 2011. Analysis of protein dynamics at active, stalled, and collapsed replication forks. Genes Dev 25: 1320-1327.

Syljuasen RG, Sorensen CS, Hansen LT, Fugger K, Lundin C, Johansson F, Helleday T, Sehested M, Lukas J, Bartek J. 2005. Inhibition of human Chk1 causes increased initiation of DNA replication, phosphorylation of
ATR targets, and DNA breakage. Mol Cell Biol 25: 3553-3562.

Tada S, Li A, Maiorano D, Mechali M, Blow JJ. 2001. Repression of origin assembly in metaphase depends on inhibition of RLF-B/Cdt1 by geminin. Nat Cell Biol 3: 107-113.

Taylor JH. 1977. Increase in DNA replication sites in cells held at the beginning of S phase. Chromosoma 62: 291 300.

Teer JK, Machida YJ, Labit H, Novac O, Hyrien O, Marheineke K, Zannis-Hadjopoulos M, Dutta A. 2006. Proliferating human cells hypomorphic for origin recognition complex 2 and pre-replicative complex formation have a defect in p53 activation and Cdk2 kinase activation. J Biol Chem 281: 6253-6260.

Thomson AM, Gillespie PJ, Blow JJ. 2010. Replication factory activation can be decoupled from the replication timing program by modulating Cdk levels. J Cell Biol 188: 209-221.

Wohlschlegel JA, Dwyer BT, Dhar SK, Cvetic C, Walter JC, Dutta A. 2000. Inhibition of eukaryotic replication by geminin binding to Cdt1. Science 290: 2309-2312.

Wong PG, Winter SL, Zaika E, Cao TV, Oguz U, Koomen JM, Hamlin JL, Alexandrow MG. 2011. Cdc45 limits replicon usage from a low density of preRCs in mammalian cells. PLoS ONE 6: e17533.

Woodward AM, Gohler T, Luciani MG, Oehlmann M, Ge X, Gartner A, Jackson DA, Blow JJ. 2006. Excess Mcm2-7 license dormant origins of replication that can be used under conditions of replicative stress. J Cell Biol 173: 673-683.

Zachos G, Rainey MD, Gillespie DA. 2003. Chk1-deficient tumour cells are viable but exhibit multiple checkpoint and survival defects. EMBO J 22: 713-723.

Zink D. 2006. The temporal program of DNA replication: New insights into old questions. Chromosoma 115: 273287. 


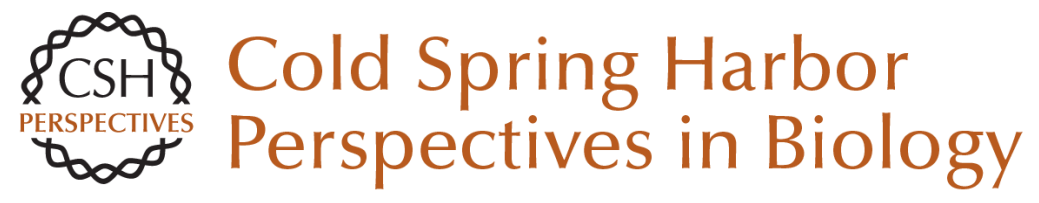

\section{Dormant Origins, the Licensing Checkpoint, and the Response to Replicative Stresses}

Debbie McIntosh and J. Julian Blow

Cold Spring Harb Perspect Biol 2012; doi: 10.1101/cshperspect.a012955 originally published online August 17, 2012

\section{Subject Collection DNA Replication}

Replication of Epstein-Barr Viral DNA

Wolfgang Hammerschmidt and Bill Sugden

Replication Proteins and Human Disease

Andrew P. Jackson, Ronald A. Laskey and Nicholas Coleman

Break-Induced DNA Replication Ranjith P. Anand, Susan T. Lovett and James E. Haber

Regulating DNA Replication in Eukarya Khalid Siddiqui, Kin Fan On and John F.X. Diffley

Archaeology of Eukaryotic DNA Replication Kira S. Makarova and Eugene V. Koonin

Translesion DNA Polymerases Myron F. Goodman and Roger Woodgate

Human Papillomavirus Infections: Warts or Cancer?

Louise T. Chow and Thomas R. Broker

Chromatin and DNA Replication

David M. MacAlpine and Geneviève Almouzni
Endoreplication

Norman Zielke, Bruce A. Edgar and Melvin L. DePamphilis

Replication-Fork Dynamics

Karl E. Duderstadt, Rodrigo Reyes-Lamothe, Antoine M. van Oijen, et al.

Helicase Activation and Establishment of Replication Forks at Chromosomal Origins of Replication Seiji Tanaka and Hiroyuki Araki

Poxvirus DNA Replication Bernard Moss

The Minichromosome Maintenance Replicative Helicase Stephen D. Bell and Michael R. Botchan

DNA Replication Origins Alan C. Leonard and Marcel Méchali

Principles and Concepts of DNA Replication in

Bacteria, Archaea, and Eukarya Michael O'Donnell, Lance Langston and Bruce Stillman

DNA Replication Timing Nicholas Rhind and David M. Gilbert

For additional articles in this collection, see http://cshperspectives.cshlp.org/cgi/collection/

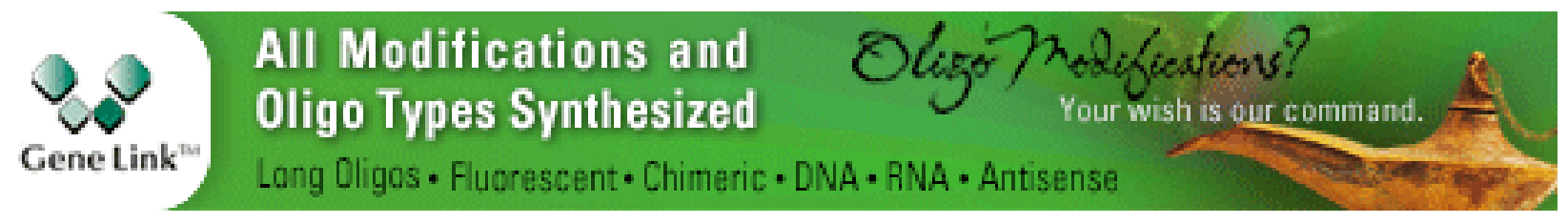

Copyright @ 2012 Cold Spring Harbor Laboratory Press; all rights reserved 